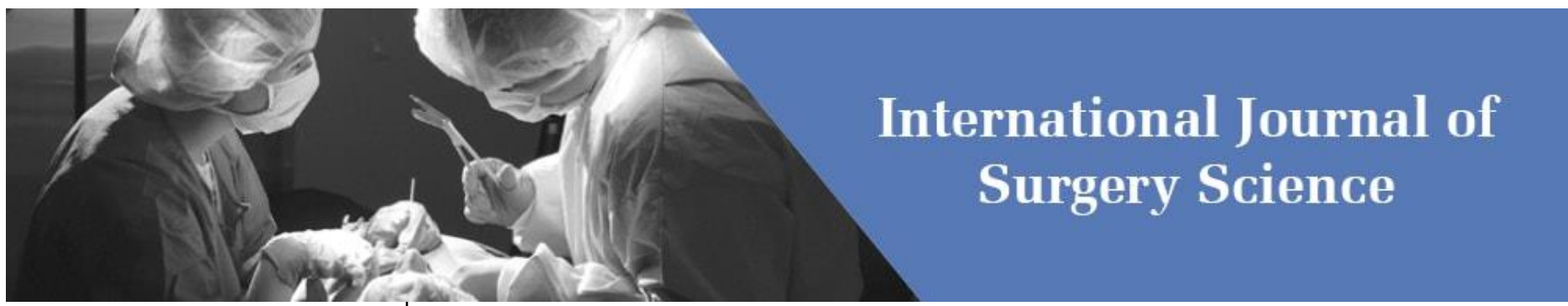

E-ISSN: 2616-3470

P-ISSN: 2616-3462

(C) Surgery Science

www.surgeryscience.com

2021; 5(1): 128-135

Received: 07-11-2020

Accepted: 12-12-2020

Dr. Preetam Penumatcha

Assistant Professor,

Katuri Medical College, Guntur,

Andhra Pradesh, India

Dr. Krishna Rao

Associate Professor,

Katuri Medical College, Guntur,

Andhra Pradesh, India

Corresponding Author:

Dr. Preetam Penumatcha

Assistant Professor,

Katuri Medical College, Guntur,

Andhra Pradesh, India

\section{Low serum testosterone and prostate cancer behaviour - any correlation}

\section{Preetam Penumatcha and Krishna Rao}

DOI: https://doi.org/10.33545/surgery.2021.v5.i1b.600

\section{Abstract}

Background and Objective: Prostate cancer is one amongst the most common medical diseases affecting elderly men. Carcinoma of the prostate is being the most common non-cutaneous cancer diagnosed. The lifetime risk of prostatic carcinoma is $16.7 \%$ and the risk of death during the entire lifetime is around $2.6 \%$ for men but the overall lifetime risk of death due to prostate malignancy is low in comparison to lifetime risk of diagnosis. Prostate cancer is a hormone dependant cancer and the clinical course of prostate cancer varies with individual and again it varies within the individual in relationship to serum testosterone levels. The present study is to find out the role of low serum testosterone level in predicting prostate cancer behaviour in comparison with normal serum testosterone level patients and to find out the relationship between low serum testosterone level and serum PSA levels in TRUS biopsy proven cancer prostate patients.

The primary aim and objective of our study is to determine the association of low serum testosterone and prostate cancer behaviour and with a Secondary objective to determine the relationship of serum PSA level in cancer prostate patients with low serum testosterone.

Methodology: Informed consent was obtained from all patients. All TRUS biopsy proven caner prostate patients were enrolled to a maximum number of 100. All details were recorded. Blood investigations like serum PSA, serum testosterone and other baseline investigations were obtained. The serum determinations of Testosterone obtained between $7-9.30 \mathrm{am}$. The serum Testosterone levels measured by appropriate standard protocols. Patients were divided into two groups based on the serum testosterone levels. Patients with low serum testosterone levels $(<250 \mathrm{ng} / \mathrm{dl})$ were categorized as Group A and patients with normal serum testosterone levels (> $250 \mathrm{ng} / \mathrm{dl}$ ) were categorized as Group B and the findings between two groups will be compared.

Results: Total of 106 patients with cancer prostate were taken into our study of which 5 patients on 5 alpha reductase inhibitors and 1 patient on testosterone replacement therapy were excluded from our study and finally 100 patients were enrolled in our study of which patients with low testosterone level $(<250 \mathrm{ng} / \mathrm{dl})$ were categorized as group A and the remaining patients with normal testosterone level (> $250 \mathrm{ng} / \mathrm{dl}$ ) were categorized as group B. The majority $(74 \%)$ of patients in low testosterone group has got a serum PSA of more than 20 values compared with only $34 \%$ of patients in the corresponding group. $\mathrm{P}$ value is found to be statistically significant. Most of the patients $(82.6 \%)$ in low testosterone group had a higher Gleason grade (8-10) compared to the normal testosterone group. $\mathrm{P}$ value is found statistically significant.

Conclusion: Low total serum testosterone is associated with higher proportion of predominant Gleason pattern 4, an indicator of aggressive prostate cancer. Patients with low serum testosterone levels were associated with an increased serum PSA levels compared with patients in normal serum testosterone levels. Patients with low testosterone who were managed by radical prostatectomy had a higher proportion of positive surgical margin, extra capsular extension and seminal Vesical invasion suggesting an aggressive prostate cancer behaviour. Preoperative total testosterone should be routinely added to serum prostate specific antigen estimation to improve prostate cancer management.

Keywords: Testosterone, prostate gland, prostatic carcinoma, PSA level

\section{Introduction}

Prostate cancer is one amongst the most common medical diseases affecting elderly men. Carcinoma of the prostate is being the most common non cutaneous cancer diagnosed in American male population. The lifetime risk of prostatic carcinoma is $16.7 \%$ and the risk of death during the entire lifetime is around $2.6 \%$ for men in United States but the overall lifetime risk of death due to prostate malignancy is low in comparison to lifetime risk of diagnosis. In developed countries carcinoma of the prostate gland is more common in the elderly male population compared with younger men. 
Around $15 \%$ of men diagnosed to have cancer of the prostate in developed world when compared to only about $4 \%$ of men in developing nations. The association of cancer prostate and serum testosterone is known for the past few decades. The benefits of surgical castration and the role of estrogen treatment on the management of metastatic cancer prostate was assessed since olden days (Huggins and Hodges, 1941) ${ }^{[2]}$. They earlier demonstrated the clinical beneficial effects of androgen suppression therapy in the management of metastatic (advanced) cancer prostate.

The androgen suppression benefits are recently extended in the management of even in non metastatic prostate cancer patients and recurrent prostate cancer after definitive management. Again there is a role for hormonal therapy in neoadjuvant settings like before radical prostatectomy which resulted in decrease in serum PSA, Shrinkage of prostate tumor volume and reduction in the rate of positive surgical margins. The reduction in prostate volume following neoadjuvant hormonal therapy is more in peripheral zone compared to central zone. Prostate cancer is a hormone dependant cancer and the clinical course of prostate cancer varies with individual and again it varies within the individual in relationship to serum testosterone levels. The present study is to find out the role of low serum testosterone level in predicting prostate cancer behaviour in comparison with normal serum testosterone level patients and to find out the relationship between low serum testosterone level and serum PSA levels in TRUS biopsy proven cancer prostate patients.

\section{Aim and objectives}

The primary aim and objective of our study is to determine the association of low serum testosterone and prostate cancer behaviour and with a Secondary objective to determine the relationship of serum PSA level in cancer prostate patients with low serum testosterone.

\section{Materials and methods \\ Inclusion criteria}

All newly diagnosed prostate cancer (TRUS guided biopsy proven) patients with age more than 40 years in our institution were enrolled.

\section{Exclusion Criteria}

- Patients already on testosterone replacement therapy

- Patients on other hormonal therapy

- Men taking medications known to lower serum PSA level (Finasteride or Dutasteride)

\section{Method of Study}

Informed consent was obtained from all patients. All TRUS biopsy proven cancer prostate patients were enrolled to a maximum number of 100. Blood investigations like serum PSA, serum testosterone and other baseline investigations were obtained. The serum determinations of Testosterone obtained between $7-9.30 \mathrm{am}$. The serum Testosterone levels measured by appropriate standard protocols. Patients were divided into two groups based on the serum testosterone levels. Patients with low serum testosterone levels $(<250 \mathrm{ng} / \mathrm{dl})$ were categorized as Group A and patients with normal serum testosterone levels (> $250 \mathrm{ng} / \mathrm{dl}$ ) were categorized as Group B and and the findings between two groups will be compared.

Clinical staging was done for all patients based on the findings in bone scan, Contrast enhanced CT Scan or MRI Scan of abdomen and pelvis. Surgery was done and all patients were followed up after one month of surgery. All prostate cancer patients who were enrolled in this study were assessed at the time of admission based on detailed clinical examination, complete baseline blood investigations, Serum PSA, Serum testosterone, Gleason grading (TRUS biopsy) which includes primary, secondary and total Gleason score or sum, Imaging studies (bone scan, CECT/MRI abdomen and pelvis and chest $\mathrm{X}$ ray). Patients with localized prostate cancers which include patients with Clinical stage $\mathrm{T} 1 \& \mathrm{~T} 2$ without regional pelvic nodal involvement and metastasis were counselled and given the option of radical prostatectomy (RP) and other patients who were in advanced stage of the disease which include clinical T3 and T4 disease and metastatic prostate cancer were managed with hormonal therapy in the form of surgical castration followed by anti-androgen therapy. Patients who underwent radical prostatectomy (RP) were followed up post operatively with histopathological specimen analysis and parameters like post operative Gleason grade, pathological tumour (PT) status, pathological node (PN) status, surgical margin status (SMS), extra capsular extension (ECE) of tumour and seminal Vesical invasion (SVI) were compared between the prostate cancer patients with low serum testosterone (group A) and normal testosterone (group B).

\section{Statistical analysis}

The patient age and serum PSA were compared with the help of Student's t-test in the low- and normal serum testosterone groups. Chi-square test (Pearson's) was applied to compare the prostate cancer parameters between low and normal serum testosterone patients. Statistical analyses were done using software SPSS version 17.0. A p value equal to or below 0.05 was taken as statistically significant.

\section{Observation and Results}

Total of 106 patients with cancer prostate were taken into our study of which 5 patients on 5 alpha reductase inhibitors and 1 patient on testosterone replacement therapy were excluded from our study and finally 100 patients were enrolled in our study of which patients with low testosterone level $(<250 \mathrm{ng} / \mathrm{dl})$ were categorized as group $\mathrm{A}$ and the remaining patients with normal testosterone level (> $250 \mathrm{ng} / \mathrm{dl}$ ) were categorized as group B. The patient demographics between the two groups are presented in the following figure.1. 


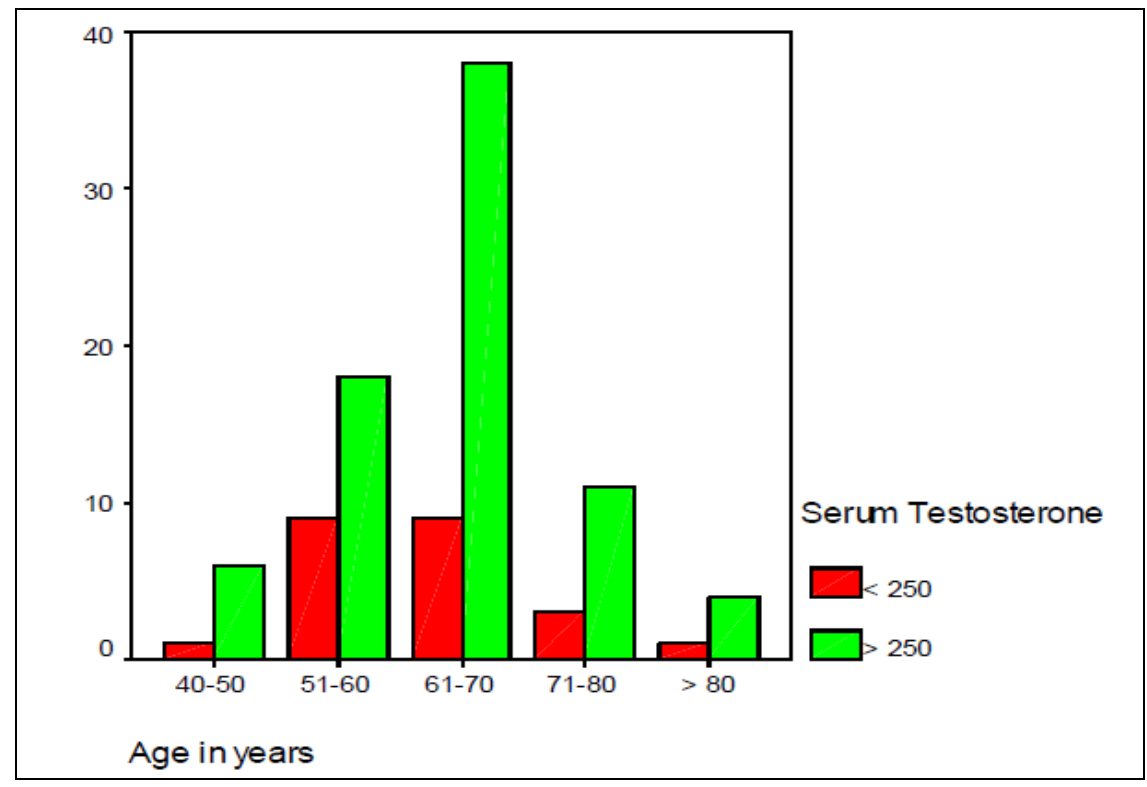

Fig 1: The patient demographics between the two groups are presented in the following

Table 1: Age in years* serum testosterone

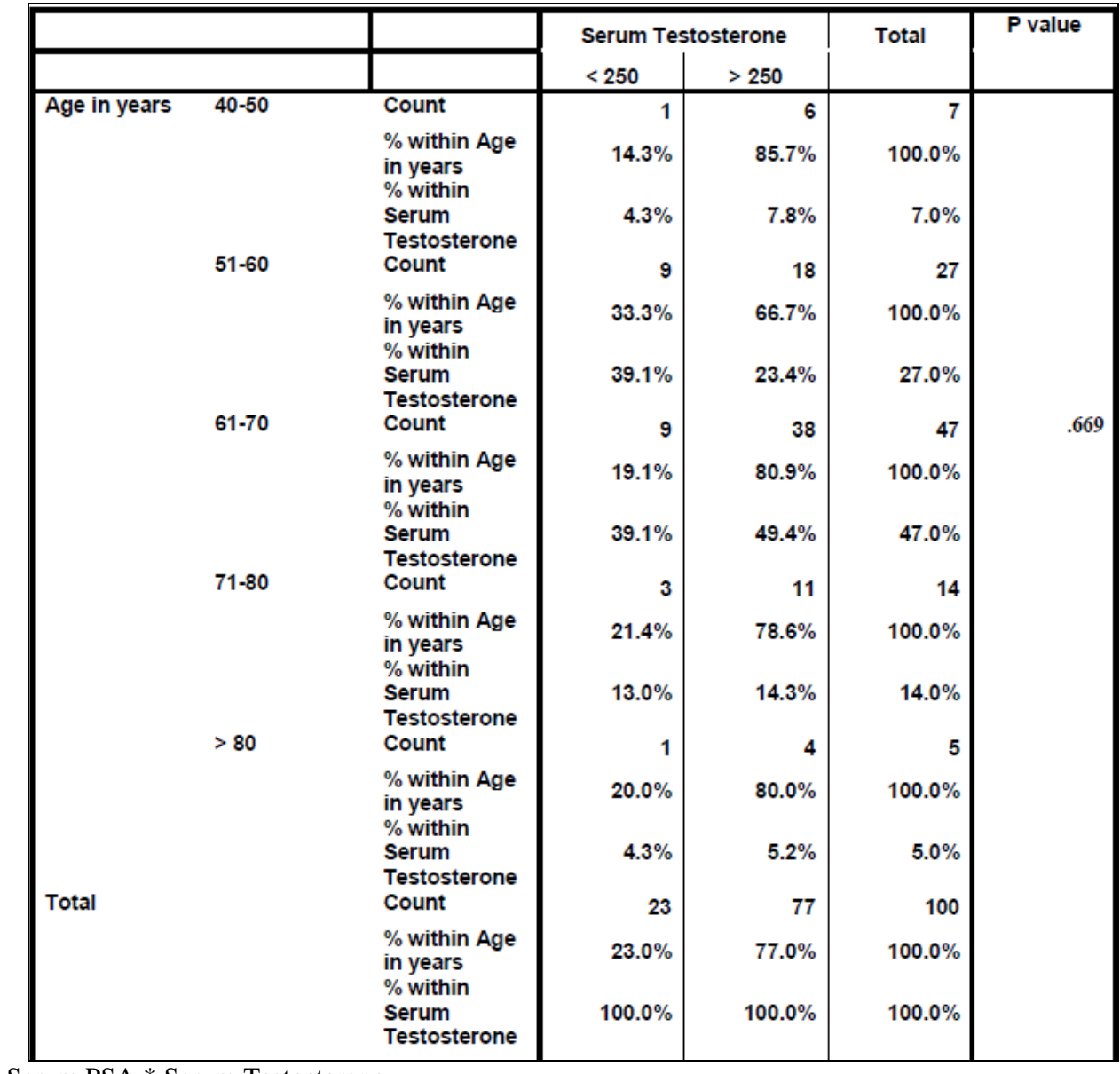

The prostate cancer patients population demographics shown in above table 1.and is found not statistically significant between the two groups. The youngest age of the patient was 45 years and oldest recorded age was 85 years.

The serum PSA levels were measured in all our study patients and the PSA levels between patients with group A and group B were analyzed and the results were depicted below in table 2 . The majority (74\%) of patients in low testosterone group has got a serum PSA of more than 20 values compared with only $34 \%$ of patients in the corresponding group. $\mathrm{P}$ value is found to be statistically significant. 
Table 2: Serum PSA * Serum Testosterone

\begin{tabular}{|c|c|c|c|c|c|c|}
\hline & & & Serum Tes & sterone & Total & $\mathrm{P}$ value \\
\hline & & & $<250$ & $>250$ & & \\
\hline Serum PSA & $<10$ & Count & 1 & 16 & 17 & \\
\hline & & $\%$ within & $5.9 \%$ & $94.1 \%$ & $100.0 \%$ & \\
\hline & & $\begin{array}{l}\text { Serum PSA } \\
\% \text { within }\end{array}$ & & & & \\
\hline & & Serum & $4.3 \%$ & $20.8 \%$ & $17.0 \%$ & \\
\hline & & $\begin{array}{l}\text { Testosteron } \\
e\end{array}$ & & & & \\
\hline & $10-20$ & Count & 5 & 35 & 40 & \\
\hline & & $\%$ within & $12.5 \%$ & $87.5 \%$ & $100.0 \%$ & \\
\hline & & $\begin{array}{l}\% \text { within } \\
\% \text { SA }\end{array}$ & & & & .003 \\
\hline & & Serum & $21.7 \%$ & $455 \%$ & $40.0 \%$ & \\
\hline & & $\begin{array}{l}\text { Testosteron } \\
e\end{array}$ & & & & \\
\hline & $>20$ & Count & 17 & 26 & 43 & \\
\hline & & $\begin{array}{l}\% \text { within } \\
\text { Serum PSA }\end{array}$ & $39.5 \%$ & $60.5 \%$ & $100.0 \%$ & \\
\hline & & $\%$ within & & & & \\
\hline & & Serum & $73.9 \%$ & $33.8 \%$ & $43.0 \%$ & \\
\hline & & & & & & \\
\hline Total & & Count & 23 & 77 & 100 & \\
\hline & & 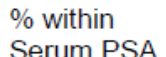 & $23.0 \%$ & $77.0 \%$ & $100.0 \%$ & \\
\hline & & $\%$ within & & & & \\
\hline & & $\begin{array}{l}\text { Serum } \\
\text { Testosteron }\end{array}$ & $100.0 \%$ & $100.0 \%$ & $100.0 \%$ & \\
\hline
\end{tabular}

TGS * Serum Testosterone

The comparison between patients total Gleason score (low $<7$, intermediate 7 and high $8-10$ ) is shown in table 3 between two groups. Most of the patients $(82.6 \%)$ in low testosterone group had a higher Gleason grade (8-10) compared to the normal testosterone group.

Table 3: TGS $*$ Serum Testosterone

\begin{tabular}{|c|c|c|c|c|c|c|}
\hline & & & \multicolumn{2}{|c|}{ Serum Testosterone } & \multirow[t]{2}{*}{ Total } & \multirow[t]{2}{*}{$P$ value } \\
\hline & & & $<250$ & $>250$ & & \\
\hline \multirow[t]{12}{*}{$\overline{T G S}$} & $<7$ & Count & 0 & 34 & 34 & \\
\hline & & $\%$ within TGS & $.0 \%$ & $100.0 \%$ & $100.0 \%$ & \\
\hline & & $\%$ within & & & & \\
\hline & & $\begin{array}{l}\text { Serum } \\
\text { Testosterone }\end{array}$ & $.0 \%$ & $44.2 \%$ & $34.0 \%$ & \\
\hline & 7 & Count & 4 & 39 & 43 & \\
\hline & & $\%$ within TGS & $9.3 \%$ & $90.7 \%$ & $100.0 \%$ & \\
\hline & & $\%$ within & & & & \\
\hline & & $\begin{array}{l}\text { Serum } \\
\text { Testosterone }\end{array}$ & $17.4 \%$ & $50.6 \%$ & $43.0 \%$ & \\
\hline & $8-10$ & Count & 19 & 4 & 23 & $<.005$ \\
\hline & & $\%$ within TGS & $82.6 \%$ & $17.4 \%$ & $100.0 \%$ & \\
\hline & & $\%$ within & & & & \\
\hline & & $\begin{array}{l}\text { Serum } \\
\text { Testosterone }\end{array}$ & $82.6 \%$ & $5.2 \%$ & $23.0 \%$ & \\
\hline \multirow[t]{4}{*}{ Total } & & Count & 23 & 77 & 100 & \\
\hline & & $\%$ within TGS & $23.0 \%$ & $77.0 \%$ & $100.0 \%$ & \\
\hline & & $\%$ within & & & & \\
\hline & & $\begin{array}{l}\text { Serum } \\
\text { Testosterone }\end{array}$ & $100.0 \%$ & $100.0 \%$ & $100.0 \%$ & \\
\hline
\end{tabular}

$\mathrm{P}$ value is found statistically significant $(<005)$.

The relation between total Gleason score (TGS) and prostate cancer patients serum testosterone levels between the two groups is shown in figure 2, as below. Patients in low testosterone group had higher proportion of high Gleason score compared to the normal testosterone group. 


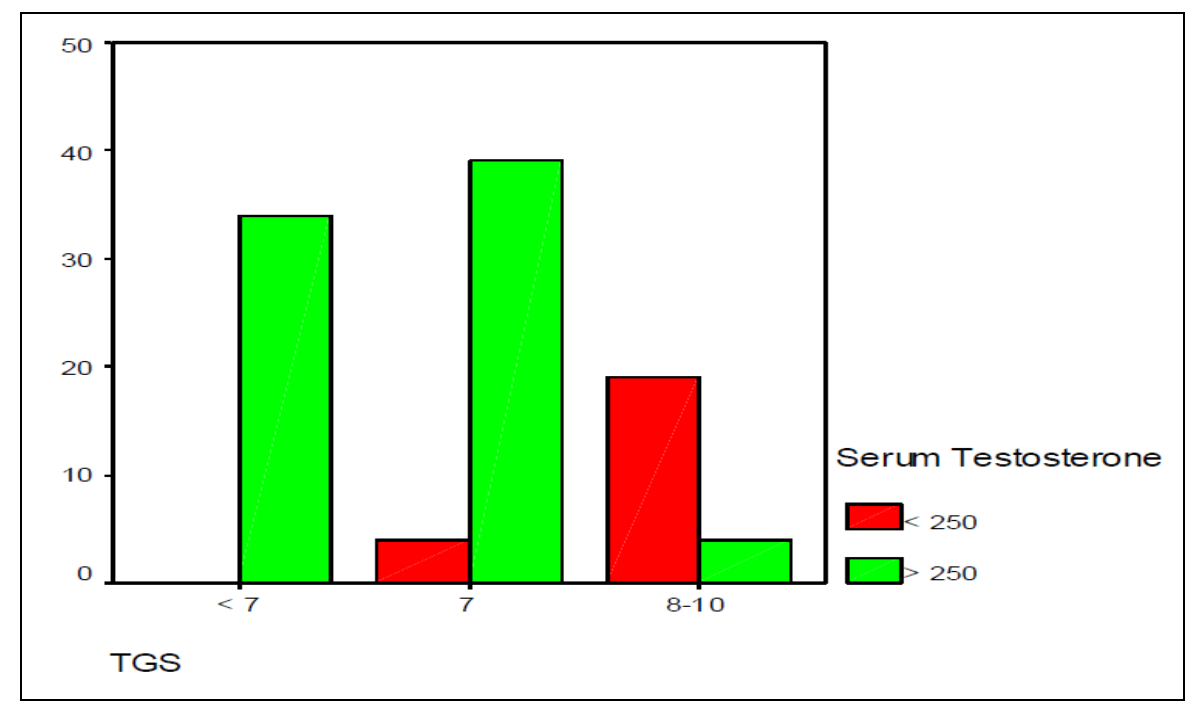

Fig 2: Clinical Stage - $\mathrm{T} *$ Serum Testosterone

Clinical tumour $(\mathrm{T})$ status, Nodal status $(\mathrm{N})$ were analyzed and the results between the two groups were represented in figure 3 , as below.

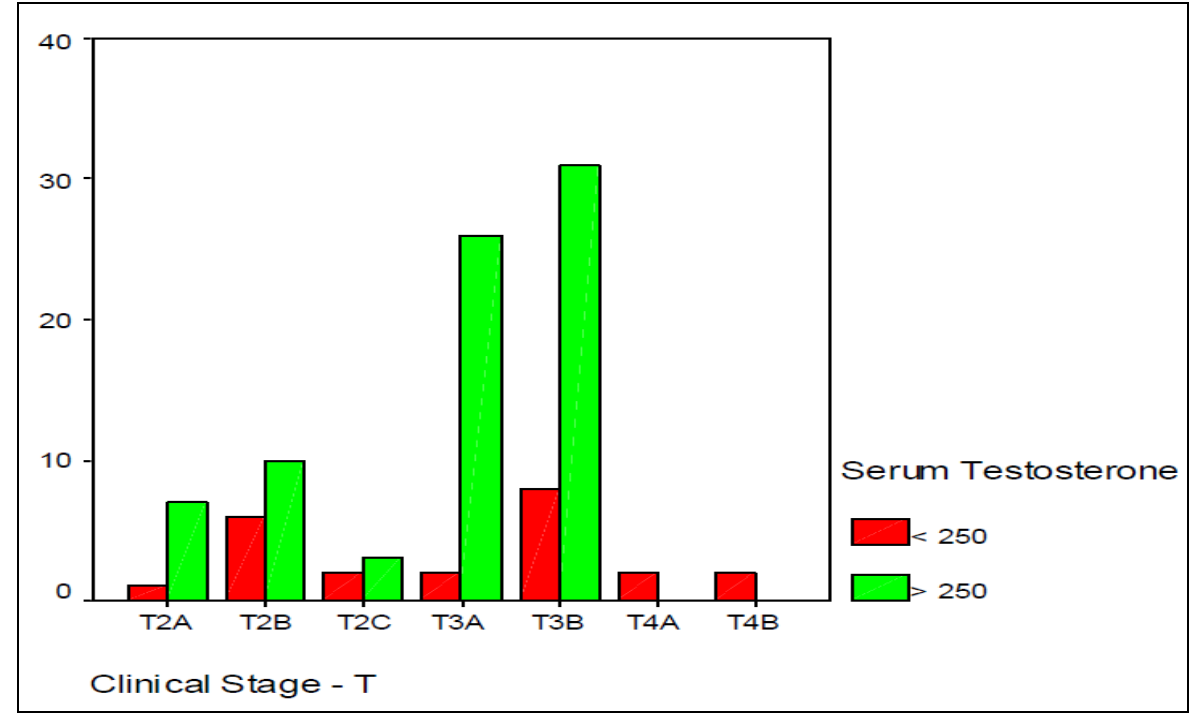

Fig 3: Clinical Stage - $\mathrm{N} *$ Serum Testosterone

Patients with low serum testosterone group had more proportion of people with nodal metastasis ( $\mathrm{N} 1$ group) than the normal

testosterone group as shown in figure 4.

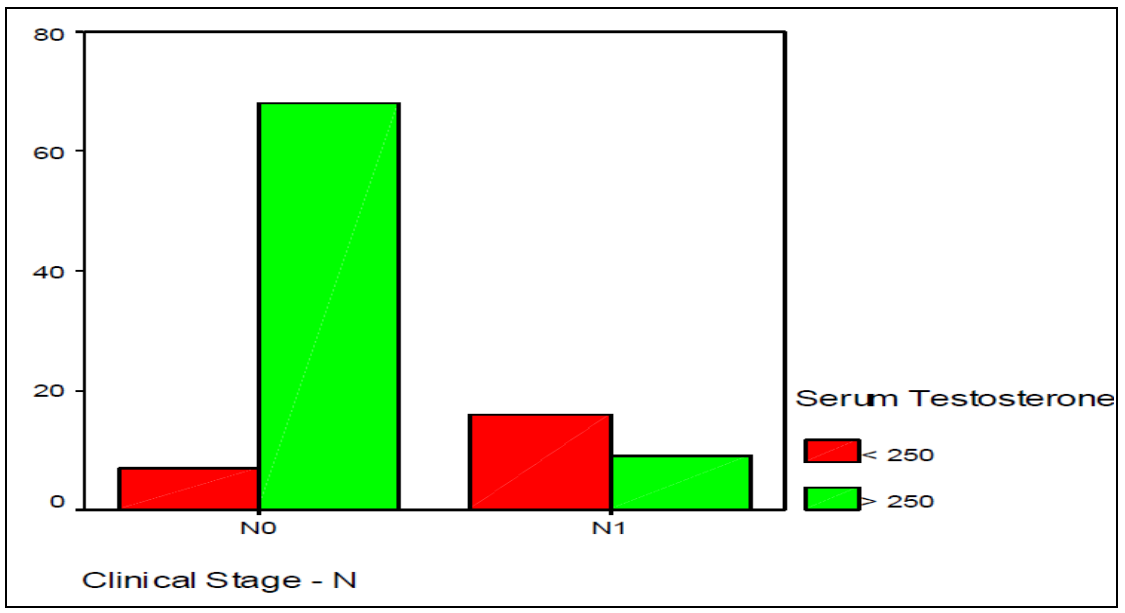

Fig 4: Management * Serum Testosterone

Management of patients in low serum testosterone and normal testosterone level were analyzed in following figure 5. 


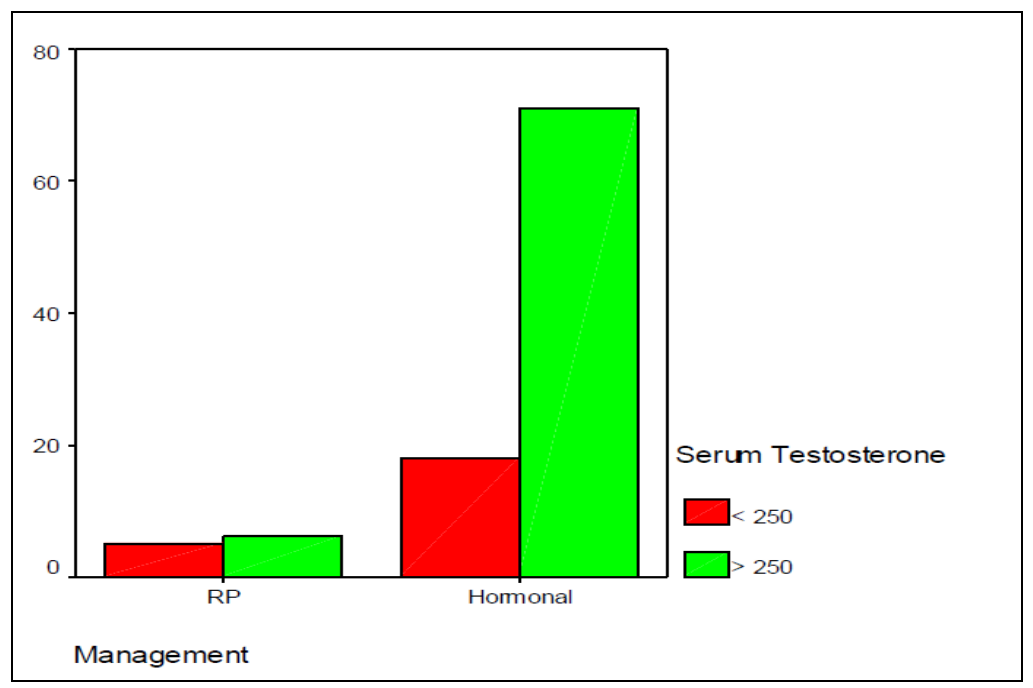

Fig 5: Post operative Gleason Grade * Serum Testosterone

Post prostatectomy histopathological specimen total Gleason score between the two groups were analyzed and shown in the following figure $6 . \mathrm{P}$ value was found statistically significant.

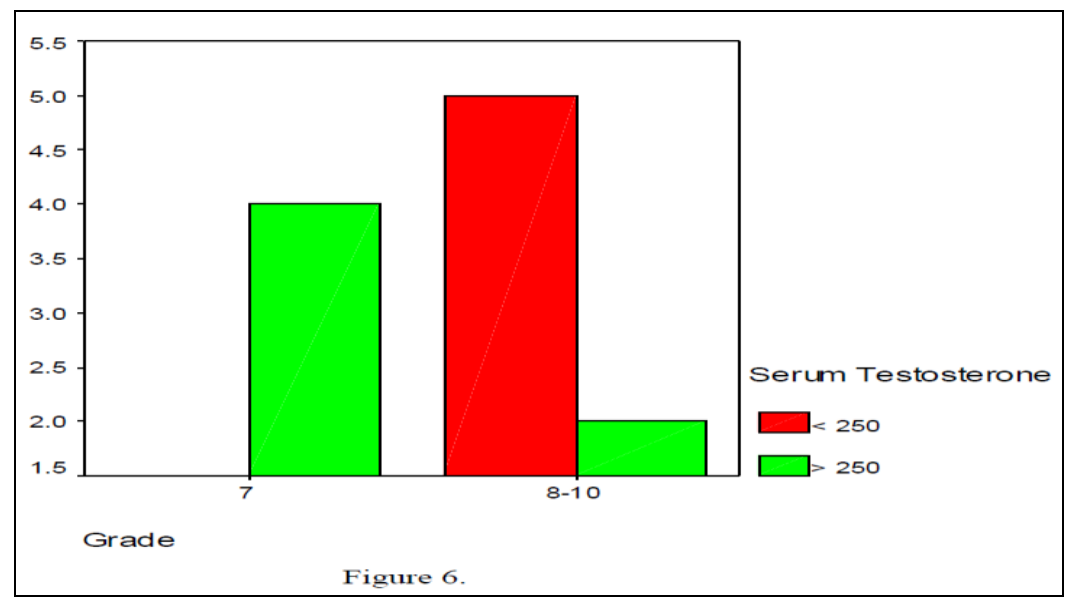

Fig 6: SMS * Serum Testosterone

The surgical margin status (SMS) between the low and normal serum testosterone group were analyzed in the following figure 7.

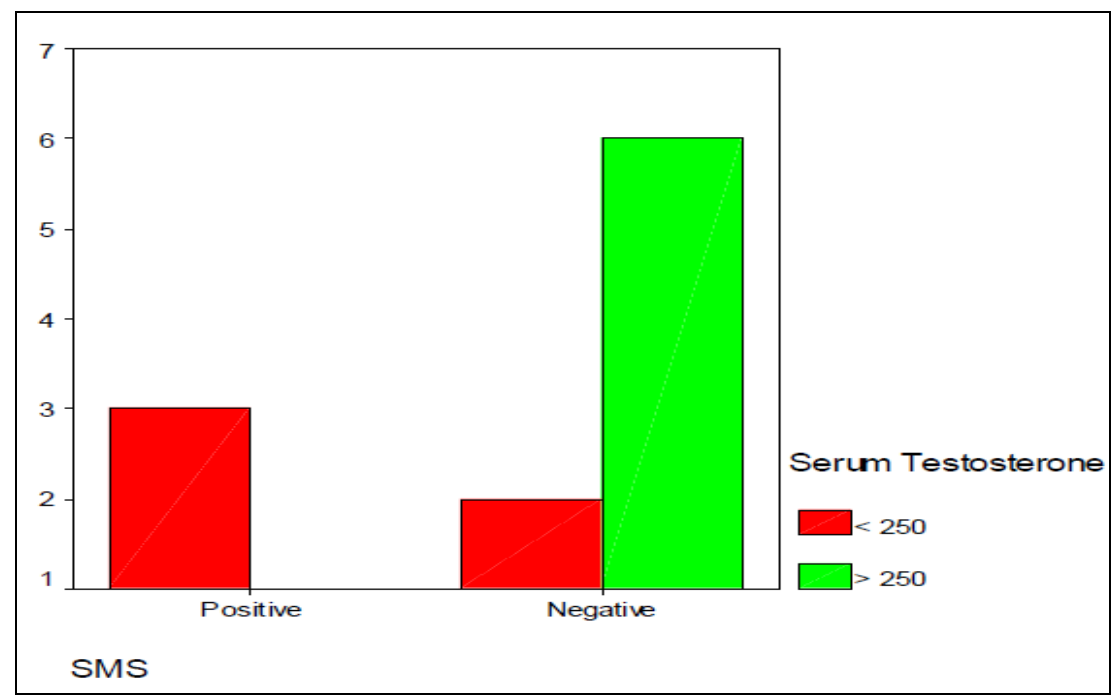

Fig 7: ECE * Serum Testosterone

Post prostatectomy histopathological specimen Extra Capsular Extension (ECE) status between the two groups were analyzed in the following figure 8 and patients in low serum testosterone group had higher positive surgical margin when compared to the normal testosterone group. 


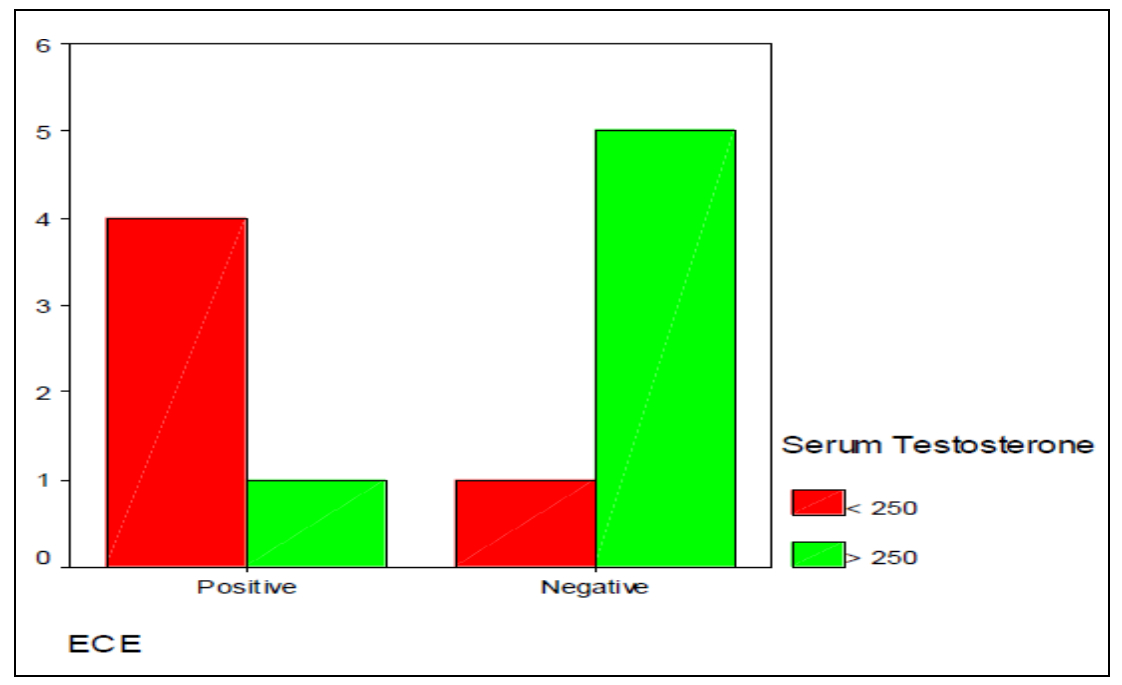

Fig 8: SVI * Serum Testosterone

Post prostatectomy histopathological specimen Seminal Vesical Invasion (SVI) status between the two groups were analyzed and were depicted in figure 9, as below. The patients in group A had more seminal Vesical invasion when compared with normal serum testosterone group.

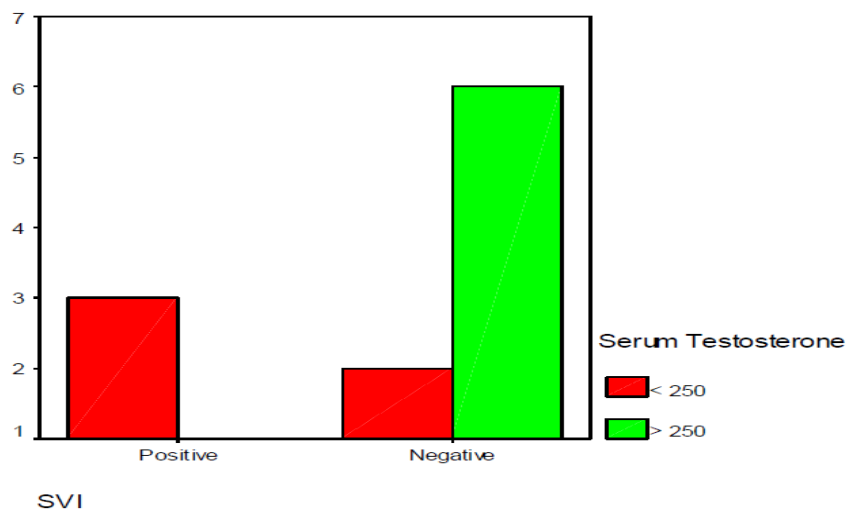

Fig 9: Post prostatectomy histopathological specimen Seminal Vesical Invasion (SVI)

\section{Discussion}

The view that Serum testosterone has got a crucial part in the development of cancer prostate is controversial and widely discussed and various studies have analyzed and documented the association between low level of serum testosterone and metastatic disease and high grade cancer prostate.

Morgentaler et al. ${ }^{[5]}$ have shown a higher incidence of cancer prostate in patients with low serum testosterone. Other studies by Massachusetts aging study have reported no association between androgens including serum testosterone and cancer prostate risk. Some of the previous studies have stated concerns about the increased risk of prostate cancer in men with lower levels of testosterone. In patients with hypogonadal clinical status and with a PSA $<4.0 \mathrm{ng} / \mathrm{ml}$, TRUS guided prostate biopsy has shown cancer in around $15 \%$, with risk of the cancer increases twice when met with greater reduction in the serum testosterone levels. The association between serum testosterone and cancer prostate is not yet well established. The possible explanation for the link between low serum testosterone and cancer prostate is due to the negative feedback effect of serum testosterone on hypothalamo pituitary axis. Miller et al. have shown that cancer prostate inhibits serum testosterone production by the hormone inhibin.
The association between low serum testosterone level and highrisk cancer prostate may be due to chronic disease induced hormonal change. In our present study, patients with low serum testosterone and its association with TRUS biopsy Gleason grade, serum PSA, Clinical Tumour (T) status, Clinical nodal (N) status, Clinical metastasis (M) status, Pathological tumour (PT) and Pathological nodal (PN) status, postoperative histopathological specimens Gleason total score, Surgical margins status, extra capsular extension and Seminal vesical invasion were analyzed in comparison with normal serum testosterone patients.

The association between low level of serum testosterone and high Gleason grade prostate cancer have been demonstrated by Zhang et al. In our study greater percentage of patients with low serum total testosterone were presented with high Gleason total scores $(\geq 8)$. Our study report was supported by similar to the study by Schatzl et al. ${ }^{[6]}$ have shown that patients with low level of serum testosterone were found to have higher Gleason total score when plotted against normal serum testosterone. Our study also shown that patients with low total testosterone level were associated with advanced clinical stage of the disease including clinical tumour status, nodal status and metastasis to bone and other viscera compared to patients with normal level of serum testosterone. The results of our study were similar to previous study done by perez Marquez et al. who found that patients with low testosterone levels are at an increased risk of metastatic disease and higher risk of tumour progression. The study by Hoffman et al. reported that patients with low serum testosterone is a marker of aggressive nature of cancer prostate. Another study also shown that serum testosterone values are an important and independent marker in assessing prostate biopsy positivity. The post prostatectomy histo-pathological specimens Gleason score, pathological tumour stage and baseline serum PSA are associated with an increased risk of aggressive prostate cancer. In our study patients with low serum total testosterone were associated with higher Gleason score and less favourable pathological stage and an increased incidence of positive surgical margins in the resected specimen, extra capsular extension of tumour either unilateral or bilateral and finally positive Seminal Vesical invasion.

There are few limitations in our study which has to be taken care in future prospective studies of similar population groups. One of the limitations is small prostate cancer population size and again the number of patients who presented with low serum levels of testosterone were only 23. Second limitation of our 
present study is number of patients who were fit under the criteria for radical prostatectomy was only 11 . Finally, the follow up period up is short and it is recommended that in the future long duration studies involving larger group of patients will be helpful in confirming our current study report and also through more light on this ever-debated prostate cancer study.

\section{Conclusion}

Low total serum testosterone is associated with higher proportion of predominant Gleason pattern 4, an indicator of aggressive prostate cancer. Patients with low serum testosterone levels were associated with an increased serum PSA levels compared with patients in normal serum testosterone levels.

Patients with low testosterone who were managed by radical prostatectomy had a higher proportion of positive surgical margin, extra capsular extension and seminal Vesical invasion suggesting an aggressive prostate cancer behaviour. Preoperative total testosterone should be routinely added to serum prostate specific antigen estimation to improve prostate cancer management.

\section{References}

1. Huggins C, Hodges CV. Studies on prostatic cancer. I. The effect of castration of estrogen and of androgen injection on serum phosphatases in metastatic carcinoma of the prostate. CA Cancer J Clin 1972;22:232-40.

2. Huggins C, Stevens RE Jr, Hodges CV. Studies on prostatic cancer. II. The effects of castration on advanced carcinoma of the prostate gland. Arch Surg 1941;43:209-23.

3. Daniell HW. A worse prognosis for men with testicular atrophy at therapeutic orchiectomy for prostate carcinoma. Cancer 1998;83:1170-3.

4. Yamamoto S, Yonese J, Kawakami S et al. Preoperative serum testosterone level as an independent predictor of treatment failure following radical prostatectomy. Eur Urol 2007;52:696-701.

5. Hoffman MA, DeWolf WC, Morgentaler A. Is low serum free testosterone a marker for high grade prostate cancer? J Urol 2000;163:824-7.

6. Schatzl G, Madersbacher S, Thurridl T et al. High-grade prostate cancer is associated with low serum testosterone levels. Prostate 2001;47:52-8.

7. Massengill JC, Sun L, Moul JW et al. Pretreatment total testosterone level predicts pathological stage in patients with localized prostate cancer treated with radical prostatectomy. J Urol 2003;169:1670-5.

8. Imamoto $\mathrm{T}$, Suzuki H, Fukasawa $\mathrm{S}$ et al. Pretreatment serum testosterone level as a predictive factor of pathological stage in localized prostate cancer patients treated with radical prostatectomy. Eur Urol 2005;47:30812.

9. Isom-Batz G, Bianco FJ Jr, Kattan MW, Mulhall JP, Lilja $\mathrm{H}$, Eastham JA. Testosterone as a predictor of pathological stage in clinically localized prostate cancer. J Urol 2005;173:1935-7.

10. Teloken C, Da Ros CT, Caraver F, Weber FA, Cavalheiro AP, Graziottin TM. Low serum testosterone levels are associated with positive surgical margins in radical retropubic prostatectomy: hypogonadism represents bad prognosis in prostate cancer. J Urol 2005;174:2178-80. 